\title{
A INFLUÊNCIA DA FIGURA E OBRA DE ROSALÍA DE CASTRO NA GALÍCIA ALÉM- MAR E A PARTICIPAÇÃO FEMININA NO CONTEXTO DA EMIGRAÇÃO
}

\author{
THE INFLUENCE OF THE FIGURE AND WORK OF \\ ROSALÍA DE CASTRO IN GALICIA OVERSEAS AND THE \\ FEMALE PARTICIPATION IN THE EMIGRATION CONTEXT
}

\author{
Bárbara Patoléa Monteiro ${ }^{1}$ \\ Universidade do Estado do Rio de Janeiro \\ Pedro Camargo Rodrigues Uzêda² \\ Universidade Federal da Bahia
}

Resumo: O presente artigo, parte importante da pesquisa de mestrado de ambos os pesquisadores, visa compreender a influência histórica do processo migratório que assolou a Galícia entre o final do século XIX e início do século XX sob os olhares de Rosalía de Castro. Apesar de sua obra estar datada até finais do século XIX, as consequências de suas produções foram além, afetando o processo de construção da migração para os galegos no novo mundo, os quais consideram Rosalía um símbolo da narrativa das dores e consequências da fuga na região. Verificamos, também, como a autora dedica uma parte de Follas Novas às mulheres galegas, tópico importante em sua obra. A metodologia utilizada passou pela análise bibliográfica de diferentes autores e temas, levando em consideração as distintas visões sobre o processo migratório galego e as construções das obras rosalianas.

Palavras-chave: América Latina; Emigração; Galícia; Mulher; Rosalía de Castro.

\footnotetext{
1 barbarapatolea@gmail.com

2 peuuzeda@gmail.com. O presente trabalho foi realizado com apoio da Coordenação de Aperfeiçoamento de Pessoal de Nível Superior - Brasil (CAPES) - Código de Financiamento 001.
} 
Abstract: The present article, an important part of the master's research of both researchers, aims to understand the historical influence of the migration process that ravaged Galicia between the end of the nineteenth century and the beginning of the twentieth century through the eyes of Rosalia de Castro. Although her work is dated to the end of the nineteenth century, the consequences of her productions went beyond, affecting the construction process of migration for Galicians in the new world, who consider Rosalia a symbol of the narrative of the pains and consequences of flight in the region. We also verified how the author dedicates a part of Follas Novas to Galician women, an important topic in her work. The methodology used went through the bibliographical analysis of different authors and themes, taking into consideration the different views on the Galician migratory process and the constructions of Rosalia's works.

Keywords: Latin America; Emigration; Galicia; Woman; Rosalía de Castro.

\section{O PROCESSO HISTÓRICO DA EMIGRAÇÃO GALEGA}

Em A Era do Capital, o historiador inglês Eric Hobsbawm apresenta um questionamento sobre os motivos das pessoas migrarem. Com isso, para ele e sua linha de pensamento atrelada à corrente historiográfica da luta de classes, as pessoas migravam "por que são pobres" (1982, p. 280) e/ou buscavam ascensão econômica e social. Afirmação que de modo algum será negada; ao contrário, o aprofundamento das variadas causas que promoveram o movimento de saída dos galegos em direção a outros lugares, especialmente à América, será uma das pautas que pretendemos alcançar.

Dito isso, é importante inferir que, por mais que se aspire abordar o movimento migratório galego e suas especificidades regionais, não se deve ignorar que a Galícia é uma região espanhola e possui, não só relação, como parâmetros diretos com seu país. Dessa forma, Ismara Izepe de Souza relata uma Espanha que chega ao século XX com cerca de 18 milhões de habitantes (2006, p. 3) e “como um país basicamente agrário, contando com uma precária unidade política e uma crise agravada pelas perdas das últimas colônias na América" (2005, p. 25) - a exemplo de Cuba e Panamá, independentes, respectivamente, em 1898 e 1903.

Contudo, por questões geográficas e políticas - como bem sinaliza Ismara Izepe, uma vez que a Espanha tinha problemas de unidade nacional e 
até os dias de hoje ainda enfrenta impasses de ordens regionalistas em detrimento do nacionalismo, a situação da Galícia foi ainda mais agravante. Para isso, analisamos o pensamento de José Ramón Campos Álvarez que entende as razões do atraso histórico da agricultura e economia galega em relação à Espanha:

culturas agrícolas pouco diversificadas, técnicas arcaicas de exploração da terra, permanência do sistema foral e de arrendamento, subdivisão extrema da propriedade da terra que resulta em pequenos lotes de terra e impede o uso de máquinas, impostos e aluguéis excessivos para economias camponesas, colheitas ruins e crises alimentares (CAMPOS ÁLVAREZ, 1994, p. 134, tradução nossa). ${ }^{3}$

Fica demarcada, portanto, a pouca diversificação do produto agrícola, bem como a subdivisão da propriedade da terra e agricultura de pequeno porte que impossibilita o uso de máquinas, gerando colheitas ruins e crises alimentares, o que fica ainda mais acentuado com o aumento da carga de impostos sobre o camponês.

Campos Álvarez (1994) vai além e credita à permanência do sistema foral como um dos pontos que leva a Galícia a um grau de subdesenvolvimento econômico e social ainda mais profundo. Sendo essa prática foral, explicada por Paulo Roberto Baqueiro Brandão (2005), como uma conjuntura análoga ao sistema feudal, uma vez que:

as famílias de agricultores despossuídos se viam na obrigação de executar as atividades inerentes ao campo em terras cuja propriedade, os chamados foros, que eram detidas por uma pequena elite (tanto a laica quanto a eclesiástica) que concedia o seu uso parcial, em troca do pagamento de pesados tributos (BRANDÃO, 2005, p. 30).

\footnotetext{
${ }^{3}$ No original: Cultivos agrarios poco diversificados, técnicas de explotación de la tierra arcaicas, permanencia del sistema foral y de rentas, extremada subdivisión de la propiedad de la tierra lo que da lugar a minúsculas labranzas e impide la utilización de maquinaria, impuestos y rentas excesivos para las economías campesinas, malas cosechas y crisis alimentícias alimentares.
} 
Para Brandão (2005), tais características tornava o trabalho contraproducente, uma vez que os lucros ficam concentrados nos dois polos detentores das terras e dos meios de produção, ou seja, a Igreja e as elites regionais. Ficava assim caracterizado, segundo Brandão, esse sistema como de cunho feudal e, consequentemente, o principal responsável por impedir as mudanças estruturais na agricultura galega que impossibilitou acompanhar o ritmo capitalista no restante da Europa (2005, p. 29). Essa afirmação casa como complementaridade ao pensamento de Campos Álvarez (1994, p. 134), uma vez que entende essa economia como primitiva, onde o dinheiro pouco circulava e os produtos agrícolas - principalmente milho, batata, laranja e uva (BRANDÃO, 2005, p. 31) - serviam muitas vezes como instrumento de troca entre os camponeses.

Importante frisar o quanto a caracterização "feudal" ou "semifeudal" é historicamente controversa, haja vista que qualquer objeto de estudo sob o olhar da ciência historiográfica jamais pode perder a noção do tempo, bem como suas condicionantes e suas estruturas. No entanto, em absoluto, não se deve menosprezar o quanto o cenário galego era economicamente desigual e tinha dificuldades em abrir-se para a industrialização.

Além disso, a partir do pensamento de Elena Pájaro Peres (2003), evidencia-se o quanto a sociedade galega, mesmo no século $X X$, é essencialmente rural, chegando, segundo a autora, a corresponder a $75 \%$ do total ser pertencente ao meio campesino já na década de 1950 (2003, p. 36). Com isso, não se deve minimizar valores de ordens outras, inclusive do âmbito geográfico e climático, para entender o sufocamento dessa região campesina antes mesmo do século XX. A exemplo do que é apontado sob o olhar antropológico de Fabiana Paixão Viana (2016), ao entender o quanto a localização geográfica galega favorável a "altos índices pluviométricos, e o 
excesso de chuva foi a principal causa para a perda de plantações inteiras" (2016, p. 28).

Somado a isso, Campos Álvarez (1994), sinaliza que tais condições vistas até agora, a exemplo da incipiente industrialização, a inexpressiva urbanização, características rurais que barraram a industrialização e até o alto índice pluviométrico - responsável por muitas vezes destruir grandes plantações agrícolas - foram agravadas pelo número crescente da taxa de natalidade e o consequente aumento demográfico, tendo consequências na divisão dos poucos recursos campesinos, como também impactos crescentes na excedente mão de obra.

Todos esses elementos já citados, de diferentes caráteres como econômico, social, cultural, geográfico e climáticos, são responsáveis, em diferentes níveis de intensidade, por colocar a Galícia na periferia, entendida como uma nomenclatura pautada nas relações de poder em contato com a Espanha. Como aponta o geógrafo Paulo Roberto Baqueiro Brandão (2005), a própria Espanha também estava distante do centro de poder europeu ao longo de todo século XIX.

Com isso, segundo Célia Braga (1995), a Galícia "fica discriminada e oprimida dentro do próprio território" (1995, p. 49), o que pode ser explicado por um projeto político de unidade espanhola na ação imperialista de Castela em aglutinar regiões no território ibérico, a exemplo da própria Galícia. Processo esse em que foram instrumentalizadas categorias de cunho histórico, cultural e linguístico (BACELAR, 1994).

Nessa conjuntura, a análise de Domingo Luis González Lopo (2003) enxerga que "A emigração seria a válvula de escape que contribuíria a moderar o crescimento da população e a produzir os recursos necessários para compensar as deficiências do sistema produtivo." (GONZÁLEZ LOPO, 2003, p. 
169, tradução nossa $)^{4}$ - explicitando dessa forma o quanto a migração foi uma forma da sociedade galega participar do mundo industrial e moderno, ao mesmo tempo em que captava recursos, em um projeto de enriquecimento, na América, com base familiar e consequências políticas e econômicas.

No entanto, mesmo sob condicionantes de crises econômicas, que perduraram durante boa parte do século XIX, marcadas por uma sociedade de base agrária e de características responsáveis por aprofundar desigualdades sociais internas da região, fatores outros não podem ser desprezados como influenciadores nas conjunturas que levaram às múltiplas correntes migratórias da Galícia.

Bacelar (2013) analisa um aspecto cultural - com base campesina - da prática do millorado. Para ele, caracteriza-se como um mecanismo de perpetuação e manutenção da casa ou do patrimônio, em um cenário de pequenas parcelas de terra. Com isso, esse mecanismo do millorado permitia que apenas um filho - não necessariamente o primogênito - pudesse herdar a propriedade dos pais e ali vivesse com a esposa e os filhos.

Dessa forma, os outros filhos poderiam morar na casa dos pais apenas na condição da solteirice. Torna-se, agora, imprescindível a análise de Fabiana Paixão Viana (2016) sobre o mesmo fenômeno, uma vez que entende a situação das opções dos irmãos que não foram contemplados pela prática do millorado como bifurcada: "ou o trabalho nas terras que não seriam suas ou a emigração" (VIANA, 2016, p. 36).

Além desse elemento cultural, José Ramón Campos Álvarez (1994) compreende também o serviço militar - ou melhor, a fuga dele - como um fator que motivou a expulsão voluntária de jovens galegos. Campos Álvarez (1994) explicita que, em um contexto de guerras durante o século XIX e a

\footnotetext{
${ }^{4}$ No original: La emigración sería la válvula de escape que contribuiría a moderar el crecimiento de la población y a producir los recursos necesarios para compensar las deficiencias del sistema productivo.
} 
consequente necessidade de um maior contingente de militares, muitos galegos optaram pela fuga clandestina em nome da sobrevivência. O que, para o autor, torna-se perceptível com a fuga de muitos rapazes galegos para Portugal já em 1835, de onde muitos desses migravam para o Brasil (1994, p. 134).

Crucial o entendimento do quanto tais condicionantes apresentadas até então, principalmente a prática do millorado, bem como a fuga do serviço militar, condicionam um maior número de migrantes do sexo masculino. E, de fato, a emigração galega é um fenômeno majoritariamente construído por homens, "o que não exclui a participação e a importância das mulheres, tanto das que partiram como das que ficaram" (SARMIENTO, 2017, p. 263).

Desse modo, apresentava-se a esse grupo feminino uma bifurcação de possibilidades: ou a mulher galega permanecia na Galícia e tornava-se responsável tanto pela casa, família e também a economia doméstica, aguardando o retorno do pai, marido ou irmão e, muitas dessas vezes, conformando-se com a solidão uma vez que muitos emigrantes nunca mais retornaram (SARMIENTO, 2017, p. 263).

Ou, tinham como segunda opção, o momento em que muitas dessas mulheres deixam de ser "viúvas de vivos" para seguir o caminho da emigração, em uma trajetória ainda mais dramática do que aqueles do sexo masculino, por conta da combinação capitalismo/machismo, pelo fato de elas só poderem exercer trabalhos menos valorizados socialmente e financeiramente (SARMIENTO, 2017). Com isso, Viana (2016) destaca um aumento no número de mulheres galegas emigradas na segunda metade do XIX, sendo esse "momento" analisado por Sarmiento (2017), mais precisamente entre 1866-1885 (VIANA, 2016, p. 33).

Importante afirmar que a situação feminina no processo histórico na fuga da Galícia - ainda que como alguém que permanece nas aldeias à espera daqueles que partiram - será objeto presente na literatura de Rosalía de 
Castro; temos nessa mulher galega alguém que entendeu a participação feminina como um agente ativo no processo migratório, independente de permanência ou saída da Galícia. Rosalía, em Follas Novas, proporciona a essas mulheres, vítimas silenciosas e pacientes, uma grande homenagem.

Todavia, antes de adentrar a obra rosaliana e ainda na construção histórica do processo migratório galego, não se pode ignorar o próprio ato ou processo da migração como um elemento de impulso para a saída dos galegos. Assim, em sua análise sobre o processo migratório galego para a Argentina, Ruy Farías (2016) credita a melhoria do transporte marítimo e a redução do custo das travessias transatlânticas, principalmente a partir do barco a vapor, como um elemento facilitador das imigrações.

Contudo, apesar de Ismara Izepe de Souza (2006) também sinalizar para uma melhoria das embarcações, um custo marítimo mais barato e com uma duração menor do tempo de trajeto, com aproximadamente de 15 a 20 dias de viagem no início do século $X X$, não se pode menosprezar "as péssimas condições sanitárias dos navios favoreciam a proliferação de doenças infectocontagiosas que faziam vítimas fatais", em que muitas dessas embarcações comportavam mais de 300 espanhóis (SOUZA, 2006, p. 7- 9).

Todavia, outro fator de empuxe foi crucial para o aumento do fluxo de migrantes saídos da Galícia. No intuito de uma melhor compreensão, é necessário estabelecer relação com o pensamento de Jeferson Bacelar (1994) em que analisa o migrante:

De volta à aldeia de origem ou através de relatos mais ou menos fantasiosos, ou pela situação econômica privilegiada que aparentavam e pelo prestígio social que passaram a desfrutar, conseguiram influenciar parentes, amigos e vizinhos, num raio de ação que ultrapassava às vezes os limites da própria aldeia (BACELAR, 1994, p. 48). 
Dessa forma, é possível inferir do entendimento de Bacelar (1994) uma situação na qual o migrante galego retorna à sua aldeia - seja para ficar em definitivo ou apenas uma breve passagem - e, a partir disso, passa a influenciar seus conterrâneos em vários aspectos à luz de uma experiência prévia em outro país: seja na nova forma de falar, na culinária, no esporte, na nova visão de mundo e na construção do desejo de seus pares também migrarem.

Assim, a partir do pensamento de Bacelar (1994), pode-se entender essa forte influência dos retornados como um elemento de empuxe para a saída de seus conterrâneos pautada no "boca a boca". Ou seja, a construção das vantagens da migração a partir de estratégias de convencimento tanto pela fala, como pelas novas posses dos retornados - por exemplo, a melhoria das vestimentas e, também, na aquisição de riquezas no próprio território galego.

Com isso, Bacelar (1994) entende historicamente de que forma "o ato de migrar incorpora-se ao simbolismo e representação das populações campesinas galegas: o mito do enriquecimento, o viajante em busca de grandes aventuras, $\mathrm{o}$ desbravador em terras e povos estranhos." (1994, p. 108).

Adentramos assim o campo identitário e, portanto, faz-se necessário uma abordagem inicial do tema tangenciado por Bacelar (1994), uma vez que a migração galega está intimamente ligada à construção da identidade galega ou "galeguidade". Como é possível verificar na obra de Eric Hobsbawm (1990), Nações e Nacionalismo desde 1780- Programa, Mito e Realidade, o final do século XIX e início do XX é marcado pela produção massiva de tradições e símbolos em que o fio condutor é a marca nacional buscando atingir uma base sólida de coesão social dentro das comunidades políticas.

Tais produções são marcadas por inúmeros elementos, como hinos, bandeiras, monumentos cívicos e grandes figuras da história da nação tidos como "heróis". Nesse contexto, em meio a formação nacional da Inglaterra, 
França, Portugal, Alemanha e Itália - cada qual respeitando suas histórias e particularidades - surge a produção identitária galega. Essa última, sob o olhar de Ramón Villares (2007), é entendida em meio ao contexto de formação nacional espanhola, em que a Galícia, bem como o País Vasco e a Catalunha não se sentiram representados por esse projeto unitário, o que, segundo Hobsbawm (1990), carateriza-se por movimentos anti-imperialistas de cunho nacionalista (1990, p. 129).

Nesse sentido, "foron aparecendo diversos proxectos nacionais alternativos que competiron ou discutiron a hexemonía do estado-nación español"5 (VILLARES, 2007, p. 24). Evidencia-se assim o quanto a formação do Estado nacional espanhol não estava dada e sim em disputa com o regionalismo. Dessa forma, Villares (2007) aponta o regionalismo de orientação liberal como um dos dois pilares que pautaram a produção dos símbolos galegos - a exemplo do hino e da bandeira oficial.

Aqui, pode-se apontar também o rexurdimento como um movimento de cunho literário galego em prol de uma valorização do galeguismo, uma vez que o século XIX é todo por ele permeado pela construção dos múltiplos nacionalismos e suas respectivas comunidades políticas imaginadas. Dessa forma, as ações de literários galegos do XIX, entre eles Rosalía de Castro, como veremos mais adiante, são centrais na construção da comunidade imaginada galega, uma vez que "o que inventa o nacionalismo é a língua impressa, e não uma língua particular em si" (ANDERSON, 2008, p. 190).

Outro pilar é centrado no papel das coletividades dos galegos migrantes, principalmente em Cuba, onde tanto o hino e bandeira da Galícia tiveram rápida aparição, com adesão popular e mobilização política em que essa coletividade "para resistir a asimilación nos países de destino, acentúa a súa

\footnotetext{
5 "Foram aparecendo diversos projetos nacionais alternativos que competiram ou discutiram a hegemonia do estado-nação espanhol" (tradução nossa).
} 
adhesión á cultura de orixe"6 (2007, p. 29). Demonstra-se, assim, ainda segundo Villares (2007), o peso da imigração galega na sua definição identitária e mobilização política.

Além desses símbolos tidos como oficiais, é possível identificar a importância e papel da migração em outros elementos dentro da sociedade galega. Essa percepção licencia o estabelecimento de uma relação plausível com a abordagem de Ana Paula Conde (2011), ao indicar que o "primeiro programa de rádio emitido integralmente em galego fosse ao ar na Argentina em 1930" (2011, p. 52) - cabe aqui uma sinalização de como a língua galega era oprimida dentro do próprio território da Galícia, o que veremos mais à frente associada as causas, efeitos e dores da migração concatenada a uma construção do nacionalismo galego.

\section{ROSALÍA DE CASTRO E A DENÚNCIA ACERCA DA SITUAÇÃO DA MULHER}

Como escreveu Ricardo Carballo Calero (1979), as letras galegas enfraquecidas desde finais da Idade Média - testemunharam o rexurdimento no século XIX. Como figura mais relevante desse momento, Rosalía de Castro proporciona à literatura galega "o primeiro testo de valor maxistral" (CARBALLO CALERO, 1979, p. 9) 7 , que vai muito além dos escritos anteriores de Vicente Turnes, Xoán Manuel Pintos e Francisco Añón. Esta mulher, nascida no dia 24 de fevereiro de 1837 na cidade de Santiago de Compostela, teve coragem para escrever versos que a fizeram figura emblemática da sua terra, tendo seu reconhecimento não só na literatura espanhola como, também, na literatura universal.

\footnotetext{
6 "Para resistir a assimilação nos países de origem, acentua a sua adesão à cultura de origem" (tradução nossa).

7 "O primeiro escrito de valor magistral" (tradução nossa).
} 
Para entendermos a obra rosaliana, é importante levarmos em conta o processo emigratório em meados do século XIX, anteriormente abordado, que cresce especialmente na década de 1860 e 1870, segundo afirma X. A. López Taboada (1978). Rosalía de Castro foi uma das vozes femininas do século que, junto com outras autoras galegas que também viriam a ter grande prestígio em território nacional, continuou o movimento de denúncia acerca do cenário de marginalização em que as mulheres se encontravam. As primeiras ocorrências desse processo de tomada de consciência advêm da Idade Média, quando algumas mulheres enfrentavam a pressão da sociedade para se manterem em silêncio e denunciavam as agressões sexuais e físicas que sofriam, como observados em alguns documentos coletados nos Textos para a historia das mulleres en Galicia (1999), como salientam Castro e Reimóndez (2013, p. 70).

Além disso, essas autoras (2013, p. 72) apontam como Rosalía teria sido precursora no cenário universal "pola súa denuncia da misoxinia que envolvía as escritoras en tanto que mulleres" ${ }^{\prime 8}$ e pela sua literatura que rompe com o modelo tradicional de feminilidade. Nesse mesmo âmbito, a autora galega escreve três obras em castelhano, intencionalmente, como forma de conciliar "o seu eu autorial feminista co galeguista" (CASTRO; REIMÓNDEZ, 2013, p. 72) ${ }^{9}$, visto que faz parte de uma conjuntura de galeguismo que está interessado nas mulheres apenas como figuras míticas:

Os pais do nacionalismo galego (entre eles, o seu marido Manuel Murguía) converteron a Rosalía na escritora galega, pois viron nela o reflexo da identidade de muller galega que pertence á comunidade nacional e encarna a muller mítica naiciña, a santiña, a gardiá das esencias da terra. Porén, esta imaxe da autora non deixa de ser unha apropiación intereseira da súa figura, pois neutraliza a dimensión social e ideolóxica da súa obra e erradica a súa rebeldía da lectura. Pero sobre todo, esa lectura intereseira oculta a face máis combativa dos seus escritos: as reivindicacións feministas

\footnotetext{
8 "Pela sua denúncia da misoginia que envolvia as escritoras enquanto mulheres" (tradução nossa).

9 "O seu eu autorial feminista com o galeguista” (tradução nossa).
} 
rosalianas [...] dos seus ensaios em castelán como Lieders (1858), A filla do mar (1859) ou As literatas. Cartas a Eduarda (1866). (CASTRO; REIMÓNDEZ, 2013, p. 72$)^{10}$.

No solene ato acadêmico na Real Academia Galega em 2015, o crítico e tradutor Basilio Losada Castro expressa, através das suas reflexões a respeito das primeiras novelas rosalianas, como a autora reivindica uma condição mais justa para a mulher na sociedade e na vida familiar. La hija del mar, publicada em 1859 quando Rosalía de Castro tinha vinte e dois anos, pode ser considerada como uma dessas primeiras manifestações literárias.

Teresa e Esperanza, as protagonistas femininas da novela, são mulheres abandonadas, "mulleres en soidade" (CASTRO, 2015, p. 11) ${ }^{11}$ vítimas de uma sociedade injusta e, principalmente, vítimas de homens como Alberto, que só encontra prazer no sofrimento que proporciona ao seu redor. Nesta obra da sua juventude, podemos descobrir materiais importantes para compreender tanto os problemas pessoais que afligiram a escritora ainda em crescimento, e que aflorariam no decorrer da sua obra, quanto o ambiente estético em que se formou.

Para o crítico Basilio Losada (2015), falar de Rosalía é falar da Galícia como "o único país do mundo construído e mantido en vida polos seus poetas, e cunha muller en cabeza deles" (2015, p. 9) ${ }^{12}$, pois, como aponta Domingo Blanco Pérez (1994), teria surgido em 1863 - sem ser precisamente literatura popular - um livro que haveria de ter uma relevância na valorização e

10 “Os pais do nacionalismo galego (entre eles, o seu marido Manuel Murguía) converteram Rosalía na escritora galega, pois viram nela o reflexo da identidade de mulher galega que pertence à comunidade nacional e encarna a mulher mítica mãezinha, a santinha, a guardiã das essências da terra. Porém, esta imagem da autora não deixa de ser uma apropriação interesseira da sua figura, pois neutraliza a dimensão social e ideológica da sua obra e erradica a sua rebeldia da leitura. Mas, sobretudo, essa leitura interesseira oculta a face mais combativa dos seus escritos: as reivindicações feministas rosalianas [...] dos seus ensaios em castelhano, como Lieders (1858), A filla do mar (1859) ou As literatas. Cartas a Eduarda (1866)" (tradução nossa).

${ }^{11}$ Mulheres em soidade" (tradução nossa).

12 "O único país do mundo construído e mantido em vida pelos seus poetas, e com uma mulher à frente deles" (tradução nossa). 
rexurdimento da cultura galega. Cantares Gallegos foi importante pelo engrandecimento da literatura popular e pela sua disseminação e influência nos mais diferentes grupos sociais. Deste modo:

Foron consideracións de orde sociolóxica, sobre todo, as que levaron a Rosalía a escribir este libro: o menosprezo, a aldraxe a Galicia e á súa cultura por parte dos de españois ignorantes pero influentes, intolerables para ela, que asume enteiramente os valores da súa cultura (e moi especialmente os da súa literatura) e reivindica a súa dignidade, a súa beleza, o seu valor, exhibindo diante do público letrado o seu idioma e os froitos escollidos da súa tradición literaria (que era a oral popular). (PÉREZ, 1994 , p. 86-87) $)^{13}$

Não há, para Losada Castro (2015), uma Rosalía que muitos já caracterizaram como "folclórica" em seu primeiro grande livro, Cantares Gallegos. Essa característica não se sustenta, pois não há folclore no livro. “O folclore mostra o pobo como espectáculo, pero, nese libro, Rosalía é a voz do pobo, dun pobo que non ten voz, e Rosalía descóbrella" (LOSADA CASTRO, 2015, p. 12) $)^{14}$.

Este desejo pelo reconhecimento da língua galega começa, como aponta María Pilar García Negro (2009, p. 196), pela sua exaltação, enriquecimento e "utilización como instrumento público"15. Afinal, é preciso estabelecer um novo modelo de normalidade, um modelo que busque deslocar dos espaços de predominância o espanhol, aquele que seria o componente invasor e de imposição, e dar lugar ao galego, componente nativo. Portanto, naturalmente

\footnotetext{
13 "Foram considerações de ordem sociológica, sobre tudo, as que levaram Rosalía a escrever este livro: o menosprezo, o insulto à Galícia e à sua cultura por parte dos de espanhóis ignorantes, mas influentes, intoleráveis para ela, que assume inteiramente os valores da sua cultura (e, especialmente os da sua literatura) e reivindica a sua dignidade, a sua beleza, o seu valor, exibindo diante do público letrado o seu idioma e os frutos escolhidos da sua tradição literária (que era a oral popular)" (tradução nossa).

14 "O folclore mostra o povo como espetáculo, mas, nesse livro, Rosalía é a voz do povo, de um povo que não tem voz, e Rosalía a descobre" (tradução nossa).

15 "Utilização como instrumento público" (tradução nossa).
} 
vai ser a língua galega o fio condutor da primeira grande obra da literatura galega contemporânea: Cantares Gallegos.

Em seus Estudos Rosalianos (1979, p. 193), Ricardo Carballo Calero expressa que o que torna a linguagem de Rosalía fascinante não é a sua contribuição à criação de um galego que seria comum, culto e literário. O seu estudo, como expressa o autor, tem um valor dialetal, pois a sua fala é testemunha de um certo momento do estado da língua. Para ele, assim como podemos estudar o galego de diferentes municípios da Espanha, também podemos estudar o galego de Rosalía, visto que recolhe distintas formas da fala rural e nos situa na conjuntura linguística daquele momento.

\section{3 "FOLLAS NOVAS" E A EMIGRAÇÃO: A ESCOLHA POR PRIVILEGIAR OS SUJEITOS FEMININOS}

Como documenta Francisco Rodríguez (2011), após o término do verão de 1880, mais especificamente no mês de setembro, apareceu um livro que afortunaria ainda mais a literatura nacional, Follas Novas. Como forma de agradecimento, Rosalía dedica o livro aos indivíduos que compõem a Sociedade de Beneficencia dos Naturales de Galicia na Habana ${ }^{16}$, da qual a fizeram sócia de honra. Suas palavras são indícios da ligação que dispunha com a emigração e do sucesso da segunda edição de Cantares Gallegos na Galícia além-mar, principalmente em Cuba:

É unha mostra de agradecemento a quen a tiña declarado socia honoraria cando se fundara, lembrándose de Cantares Gallegos, como unha expresión de amor pola patria ausente, xusto cando sae a segunda edición, que había de espallarse de forma importante na emigración, consagrando o nome de

\footnotetext{
${ }^{16}$ Em 1871, dezenas de emigrantes galegos se reuniram em um dos mais antigos teatros de Havana, o Teatro de Albisu, dando início a uma das organizações filantrópicas mais significativas criadas por galegos da Galícia além-mar.
} 
Rosalía como poeta representativa de Galiza. (RODRÍGUEZ, 2011, p. 319$320)^{17}$

O progresso da literatura nacional tinha padecido, como bem sinaliza Francisco Rodríguez (2011), “certa demora desde 1872, sendo Follas Novas a principal vítima, xa que aparecera anunciada desde ese mesmo ano, tardando oito en ver a luz" (RODRÍGUEZ, 2011, p. 320)18. Os motivos para esse grande intervalo de tempo são explicados através de dois indicativos: como exprime Claude Poullain (1989), não podemos deixar de considerar as adversidades que encontra Rosalía no meio familiar, principalmente após o nascimento dos filhos, além das distintas dificuldades com a chegada da Restauração (1875) ${ }^{19}$.

Para Catherine Davies (1990), outro aspecto importante é a precariedade de editoras galegas e as muitas brigas de Manuel Murguía com a imprensa, sobretudo com Lamas Carvajal, fundador e diretor do periódico El Heraldo Gallego, que costumava publicar os poemas de Rosalía. Essa conjuntura leva Follas Novas, como esclarece Anxo Angueira (2016, p. 15-16), a ver a luz através de duas empresas que pertenciam a um velho amigo do casal, Alejandro Chao: em Cuba, onde estava localizada a editora La Propaganda Literaria, e em Madri, onde a obra foi impressa e, posteriormente, distribuída.

Follas Novas é o livro mais radical, ao mesmo tempo o mais dialético, social e histórico da autora. Apresenta uma clara intenção globalizadora e coletiva, não sendo somente íntimo e confessional. Os poemas presentes nessa obra surgem em um ambiente de grande tristeza e dor, e o título é considerado

\footnotetext{
17 “É uma demonstração de agradecimento a quem a tinha declarado sócia honorária quando se fundara, lembrando-se de Cantares Gallegos, como uma expressão de amor pela pátria ausente, justo quando sai a segunda edição, que havia de se espalhar de forma importante na emigração, consagrando o nome de Rosalía como poeta representativa da Galícia" (tradução nossa).

18 "Certa demora desde 1872, sendo Follas Novas a principal vítima, já que aparecera anunciada desde esse mesmo ano, tardando oito em ver a luz" (tradução nossa).

${ }^{19}$ De fevereiro de 1873 até dezembro de 1874, a Espanha foi governada pelo regime político republicano. Este período, marcado por violência e instabilidade, durou apenas poucos meses, sendo logo substituído pela restauração da monarquia bourbônica.
} 
por Rosalía contraditório e irônico com as realidades de miséria e angústia individuais e coletivas (RODRÍGUEZ, 2011).

O fato de ser um livro que esteve em elaboração durante longos anos faz com que o resultado seja positivo por apresentar uma maturidade em sua estrutura geral. Angueira (2016, p. 18) explica que a obra é um conjunto de 137 poemas e mais de 4.600 versos dispostos em cinco partes, na qual cada uma delas apresenta um critério temático. De certo modo, Follas Novas é um livro de livros, sendo ele composto por: Vaguedás, Do íntimo, Varia, Da terra e As viúdas dos vivos e as viúdas dos mortos. A própria Rosalía menciona no índice final como cada uma das partes são designadas como Livro I, Livro II, Livro III, Livro IV e Livro $V$.

As viúdas dos vivos e as viúdas dos mortos, com seus 31 poemas, é o livro que se centra no tema da emigração, especialmente na figura da mulher, "suxeitos líricos de moitos poemas" (RODRÍGUEZ, p. 346)²0. Claude Henri Poullain (1989), por sua vez, considera que está plenamente dedicado “ás mulleres casadas galegas"' (1989, p. 170)21. Essas mulheres estão na condição de viúvas porque seus homens partem para a América, com o intuito de fugirem da miséria. Muitas vezes, morrem antes mesmo de poderem voltar para sua terra natal; em outras, casam-se novamente, se estabelecem naquele novo território e abandonam a sua família, que continua esperando. O grandioso movimento emigratório para Cuba está narrado no poema que abre o Livro V, "Pra a Habana!" (CASTRO, 2016, p. 301-304) como uma forma de introdução, descrevendo o momento em que os homens deixam suas mulheres:

\section{I}

Vendéronlle os bois, vendéronlle as vacas,

\footnotetext{
20 "Sujeitos líricos de muitos poemas" (tradução nossa).

21 "Às mulheres galegas casadas" (tradução nossa).
} 
o pote do caldo

i a manta da cama.

Vendéronlle o carro

i as leiras que tiña;

deixárono sóio

coa roupa vestida.

"María, eu son mozo,

pedir non me é dado;

eu vou polo mundo

pra ver de ganalo.

Galicia está probe,

i á Habana me vou...

¡Adiós, adiós, prendas

do meu corazón!" (p. 301)

$\mathrm{V}$

Éste vaise i aquél vaise,

e todos, todos se van.

Galicia, sin homes quedas

que te poidan traballar.

Tes, en cambio, orfos e orfas

e campos de soledad,

e nais que non teñen fillos

e fillos que non tén pais.

E tes corazóns que sufren

longas ausencias mortás,

viudas de vivos e mortos

que ninguén consolará. (p. 304)

Poullain (1989) esclarece que o sofrimento delas é uma das condições de desgraça da Galícia, visto que o motivo da saída dos homens é a fome. Antes de tudo, os homens que precisam abandonar suas famílias são vítimas, não podendo ser completamente responsabilizados pela triste posição das mulheres. No entanto, é notório que são elas que se encontram nas piores situações, "porque tem que aguantar á vez a miseria e a soidade, mentres que o home, alén mar sabe que non voltará; mais non por iso deixa de serlle fiel." $(1989, \text { p. } 171)^{22}$

\footnotetext{
22 "Porque tem que aguentar de uma vez a miséria e a saudade, enquanto que o homem, alémmar, sabe que não voltará; mas nem por isso deixa de ser-lhe fiel" (tradução nossa).
} 
Rosalía de Castro se sensibilizou com a dor e o esquecimento em que as mulheres da sua terra se encontravam, valendo das suas próprias palavras para exprimir-se. De uma maneira especial, estabelece sua preocupação com o grupo social das mulheres trabalhadoras, pois elucidam, como Francisco Rodríguez (2015) sinaliza, uma "dobre marxinación, económico-social e psicolóxica" (RODRÍGUEZ, 2011, p. 351)23. Antes de mais nada, isso não faz com que a autora não se preocupe com os homens. Rosalía entende que existam indivíduos que podem sofrer "o odio e o desprezo como marxinados psicolóxicos, e non só as mulleres" (RODRÍGUEZ, 2011, p. 351)²4. Um exemplo disso é o poema "Era no mes de maio", no qual podemos encontrar a tentativa de suicídio de um homem amargurado:

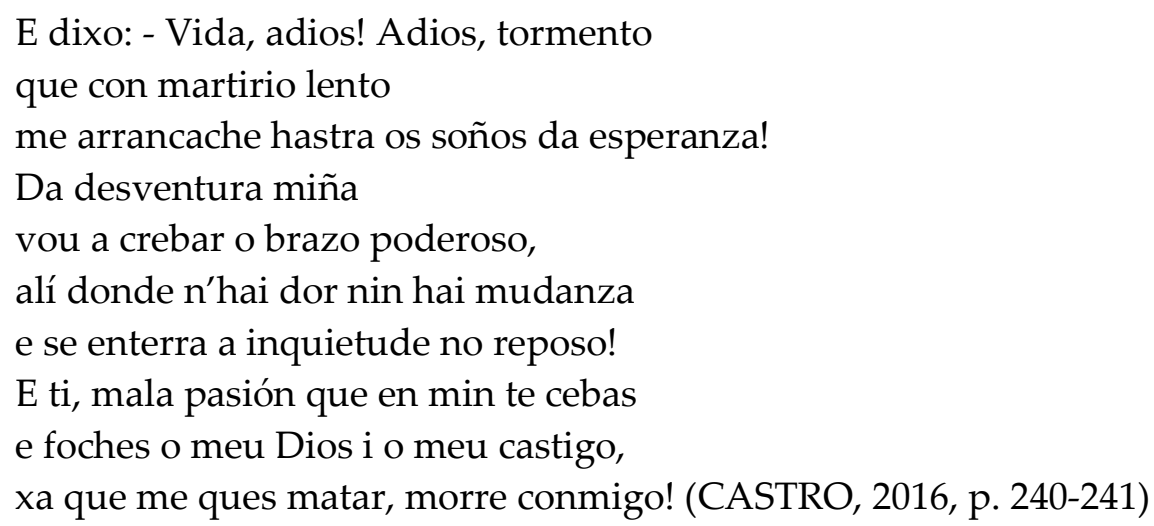

Em grande parte dos poemas do Livro V, a mulher necessita simplesmente expressar sua dor de forma sincera. Muitas vezes estabelece um diálogo consigo mesma, com a sua própria consciência, com a natureza, e até mesmo com os animais que fazem parte do seu mundo cotidiano. Entretanto, um dos diálogos mais comoventes, como expõe Claude Henri Poullain (1989), é o que se estabelece com o homem que partiu, a recordação que possui dele traz, às vezes, conforto, mas também um motivo de sofrimento (POULLAIN, 1989, p.

\footnotetext{
23 "Uma dupla marginalização, econômica, social e psicológica" (tradução nossa). 24 "O ódio e o desprezo como excluídos psicologicamente, e não só as mulheres" (tradução nossa).
} 
176), como podemos verificar nos poemas "Tecín soia a miña tea" e "Non coidarei xa os rosales":

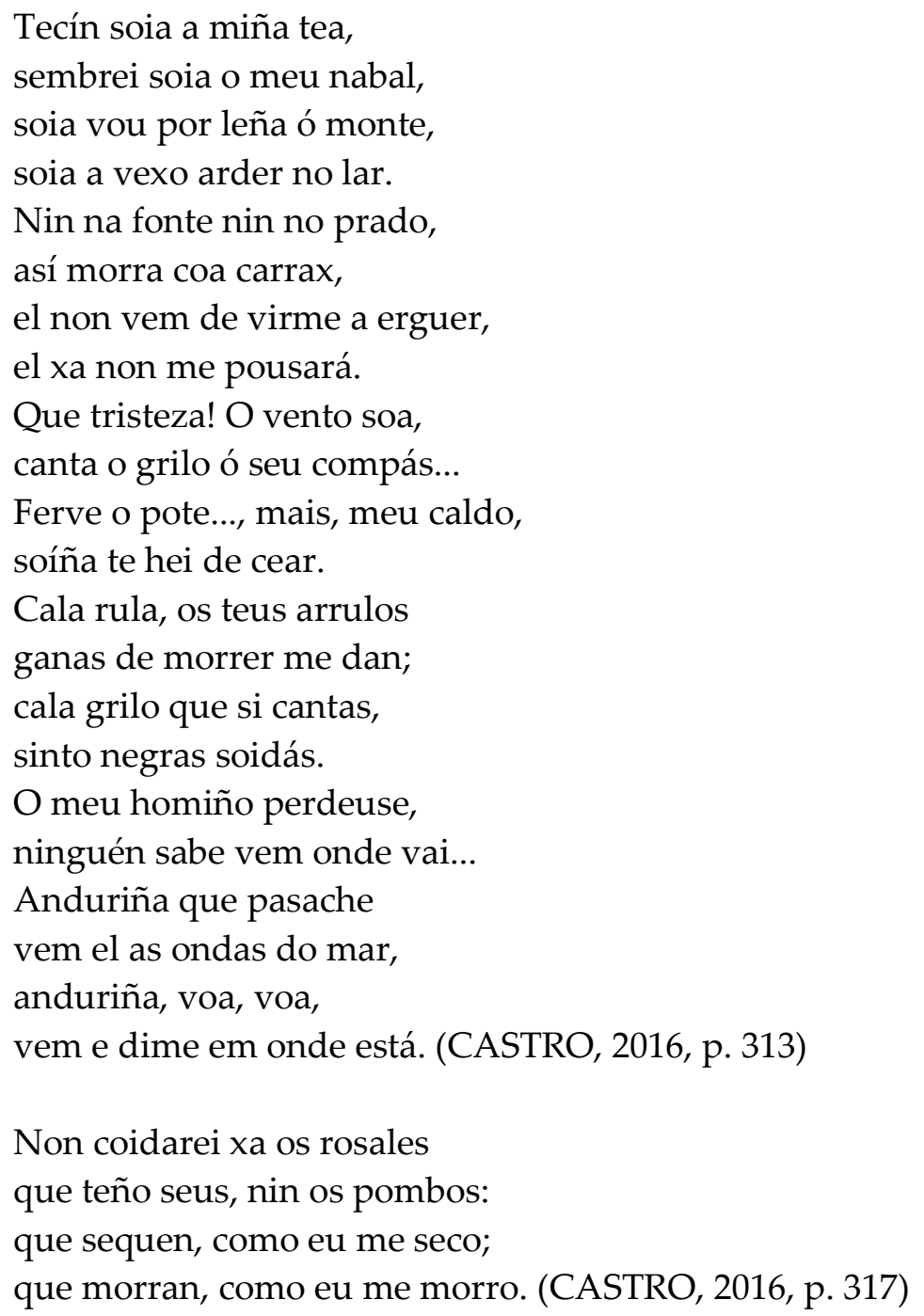

Em muitos poemas de Follas Novas, percebemos que as mulheres estão inseridas em um contexto no qual o homem está ausente pelo fenômeno da emigração. Contudo, em alguns casos, são elas as que estão distantes da terra ou resolvem emigrar ("De soidás morríase" e "Cá pena ó lombo"), acabando por sofrer uma dupla saudade, como no exemplo de "Tan soio": a saudade da terra e a saudade do homem (RODRÍGUEZ, 2011, p. 346): 
Os dous da terra lonxe

andamos e sufrimos, ai de min!

Mais ti tan soio te recordas dela

i eu dela e mais de ti.

Ambos errantes polo mundo andamos

i as nosas forzas acabando van.

Mas, ai!, ti nela atoparás descanso

i eu tan soio na morte o hei de atopar. (CASTRO, 2016, p. 345)

\section{CONSIDERAÇÕES FINAIS}

Em Historia das mulleres em Galicia (2011), compreendemos que a emigração desempenha um importante papel no regime demográfico galego. Observamos que há dois tipos de mulheres que estão relacionadas com a temática migratória: as que padecem, sem estarem diretamente ligadas com o fenômeno da emigração, precisando assumir os trabalhos que antes eram desempenhados pelos homens; e as que estão ativamente introduzidas na corrente migratória, o que aumenta à medida que a segunda metade do século XIX vai se desenrolando.

No entanto, é fundamental salientar que só a partir da década de 1930 constatamos que a atuação das mulheres nos movimentos migratórios se equipara aos $30 \%$ :

Emigraron menos e máis tarde, pero cando o fixeron foi de forma máis definitiva que no caso dos homes, cuxo retorno, aínda que fose temporal, foi máis frecuente mentres a muller non emigrou. Dos varóns retorna $30 \%$ mentres que das mulleres só volven 16 cada 100. (PERNAS OROZA; REY CASTELAO, 2011, p. 34) $)^{25}$

O destino favorito da emigração feminina era a Argentina e, entre 1885 e 1886, cerca de 2.000 mulheres das regiões de Pontevedra e A Coruña partiram

\footnotetext{
25 "Emigraram menos e mais tarde, mas, quando o fizeram, foi de forma mais definitiva que no caso dos homens, cujo retorno, ainda que fosse temporal, foi mais frequente, enquanto a mulher não emigrou. Dos homens, 30\% retornam, enquanto que no caso das mulheres só voltam 16 de cada 100" (tradução nossa).
} 
para o país. Ainda que de forma mais moderada, também podemos citar Uruguai como um dos países escolhidos, já que a maior parte dos emigrantes galegos eram homens. Em relação a Cuba, entretanto, a integração da mulher no cenário migratório também ocorreu em menor número, mas de forma tardia (PERNAS OROZA; REY CASTELAO, 2011).

Um dos indicativos da importância que teve Rosalía foi que apesar da ditadura franquista ter silenciado a obra da poetisa, como aponta Víctor Fuentes (2007) - no final do primeiro terço do século XX e com a ascensão política de Francisco Franco ao poder - na emigração e no exílio seguiram publicando e lendo a obra da autora. Temos como exemplo o fracasso, devido à ocupação do exército franquista na Galícia, dos preparativos da celebração do centenário do nascimento de Rosalía, na qual teria lugar em Santiago de Compostela. Por outro lado, no final de julho de 1939, durante a semana dos dias 22 a 29, em Buenos Aires, foi realizado um grande tributo em comemoração ao seu centenário.

Rosalía de Castro é uma das figuras das letras galegas mais comentadas e estudadas, dentro e fora do território espanhol. Mais de um século depois da sua morte, a poetisa ganhou um espaço mais que merecido nas literaturas de língua espanhola, e não nos deixou dúvidas de que através de suas próprias experiências conseguiu fazer uma poesia que foi capaz de ter alcance universal (MAYORAL, 2008). Henri Poullain (1989, p. 345-346) nos lembra que sua obra se encaixa de forma impecável dentro da literatura do século, sendo "herdeira dunha producción literaria que ela coñecía moi ben, e que exerceu unha influencia notable na súa propia obra"26; ainda que essa condição não a impediu de transformá-la do seu jeito, deixando traços da sua personalidade e galeguismo.

\footnotetext{
26 "Herdeira de uma produção literária que ela conhecia muito bem, e que exerceu uma notável influência em sua própria obra" (tradução nossa).
} 


\section{REFERÊNCIAS}

ANDERSON, Benedict. Comunidades imaginadas: reflexões sobre a origem e a difusão do nacionalismo. São Paulo: Companhia das Letras. 20008.

ANGUEIRA, Anxo. A xénese. In: CASTRO, Rosalía. Follas Novas. Vigo: Xerais, 2016.

BACELAR, Jeferson. Galegos no paraíso racial. Salvador: Ianamá, 1994.

BRAGA, Célia Maria Leal. Memórias de imigrantes galegos. Salvador: Centro Editorial e Didático da UFBA, 1995.

BRANDÃO, Paulo Roberto Baqueiro. Geografias da presença galega na cidade de Bahia. Salvador: EDUFBA, 2005.

CAMPOS ÁLVAREZ, José Ramón. La emigración gallega a América (1880-1930) integración y retorno. Revista Minius do Departamento de História, Arte e Xeografia. Vigo: n. 2-3, p.133-145, 1994.

CARBALLO CALERO, Ricardo. Estudos rosalianos. Aspectos da vida e da obra de Rosalía de Castro. Vigo: Galaxia, 1979.

CASTRO, Olga; REIMÓNDEZ, María. Feminismos. Edicións Xerais, 2013.

CASTRO, Rosalía. Follas Novas. (ed. Anxo Angueira). Vigo: Edicións Xerais, 2016.

CONDE, Ana Paula. Da emigração à diáspora: positivação de uma identidade. 2011. 260 f. Tese. (Doutorado em História, Política e Bens Culturais). Centro de Pesquisa e Documentação de História Contemporânea do Brasil, Programa de Pós-Graduação, Fundação Getúlio Vargas, Rio de Janeiro.

DAVIES, Catherine. Rosalía de Castro e Follas Novas. Vigo: Galaxia, 1990.

DIAS Y GARCÍA-TAVALERA, Miguel. Dicionário Santillana para estudantes: espanholportuguês, português-espanhol. São Paulo: Moderna, 2014.

FARÍAS, Ruy. Migraciones y exilios gallegos en la Argentina (ss. XVIII-XXI): algunos comentarios a la bibliografía sobre el tema. Memoria Académica. La Plata, vol. 17, n. 25, e008, p. 2-24. 2016.

FUENTES, Víctor. Vigencia y exaltación de Rosalía de Castro em los escritores gallegos del exilio. Actas do VII Congreso Internacional de Estudos Galegos. Mulleres en Galicia. Galicia e os outros pobos da Península. Barcelona 28 ó 31 de maio 2003. Ed. de Helena González e M. Xesús Lama. Sada: Ediciós do Castro; Asociación Internacional de Estudos Galegos (AIEG); Filoloxía Galega (Universitat de Barcelona), 2007.

GALDO, María Xosé Rodríguez; CARIDAD, Eva Castro. Textos para a historia das mulleres en Galicia. Consello da Cultura Galega, 1999.

GONZÁLEZ LOPO, Domingo Luis. Migraciones Históricas de los Gallegos en el Espacio Peninsular (Siglos XVI-XIX). Obradoiro de Historia Moderna. Santiago de Compostela, n. 12, p. 167-182, 2003.

HOBSBAWM, Eric. A era do capital. Rio de Janeiro: Paz e Terra, 1982. 
HOBSBAWM, Eric. Nações e nacionalismo desde 1780: programa, mito e realidade. Rio de Janeiro: Paz e Terra, 1990.

LOSADA CASTRO, Basilio. Reflexións sobre as primeiras novelas de Rosalía de Castro. A Coruña: Real Academia Galega, 2015. (Discurso)

MAYORAL, Marina. La poesía de Rosalía de Castro. Alicante: Biblioteca Virtual Miguel de Cervantes, 2008.

NEGRO, María Pilar García. De Rosalía a Castelao: o rosto verdadeiro da Galiza. In: FONTAIÑA, Laura Tato; MALEVAL, Maria do Amparo Tavares (Org.). Estudos galegobrasileiros 3: língua, literatura, identidade. De Letras, 2009. p. 193-201.

PERES, Elena Pajaro. A inexistência da terra firme. A Imigração Galega em São Paulo, 1946-1964. São Paulo: EDUSP/IMESP/FAPESP, 2003.

PÉREZ, Domingo Blanco. Historia da literatura popular galega. Santiago de Compostela: Universidade de Santiago de Compostela, 1994.

PERNAS OROZA, Herminia; REY CASTELAO, Ofelia. Historia das mulleres en Galicia: Época contemporánea. Xunta de Galicia, Secretaria Xeral de Igualdade, 2011.

POULLAIN, Claude. Rosalía de Castro e a súa obra literaria. Editorial Galaxia, 1989.

RODRÍGUEZ, Francisco. Rosalía de Castro, estranxeira na súa patria. A Coruña: Asociación socio-pedagóxica GA, 2011.

SARMIENTO, Érica. Galegos nos trópicos: invisibilidade e presença da imigração galega no Rio de Janeiro (1880-1930). Porto Alegre: EDIPUCRS, 2017.

SOUZA, Ismara Izepe de. Espanhóis: história e engajamento. São Paulo: Nacional, 2006.

SOUZA, Ismara Izepe de. Solidariedade internacional: a comunidade espanhola do Estado de São Paulo e a polícia política diante da guerra civil da Espanha (1936-1946). São Paulo: Humanitas/Fapesp, 2005.

TABOADA, Xosé Antonio López. Economía e población en Galicia. Edicións Do Rueiro, 1978.

VIANA, Fabiana Paixão. A mesa galega na Bahia: a alimentação dos imigrantes galegos e descendentes em Salvador. 2016. 164 f. Tese. (Doutorado em Antropologia) Faculdade de Filosofia e Ciências Humanas, Universidade Federal da Bahia, Salvador.

VILLARES, Ramón. Producir Símbolos Nacionais. In: Org: FERNANDÉZ, Xosé Ramón Barreiro e VILLARES, Ramón. Os símbolos de Galícia. Coruña, Santiago de Compostela. Consello da Cultura Galega. 2007. p. 11- 22.

Nota do editor:

Artigo submetido para avaliação em: 08 de março de 2021.

Aprovado em sistema duplo cego em: 10 de julho de 2021. 